\title{
How no one acted when they should have
}

\author{
A retired maxillofacial surgeon had a revision of a 14 year old hip replacement, after which he had \\ an unpleasant series of side effects
}

\author{
Russell Hopkins patient ${ }^{1}$, Gavin Werrett consultant anaesthetist ${ }^{2}$ \\ ${ }^{1}$ Cardiff, UK ; ${ }^{2}$ Department of Anaesthesia, Derriford Hospital, Plymouth PL6 8DH
}

\begin{abstract}
This is one of a series of occasional articles by patients about their experiences that offer lessons to doctors. The BMJ welcomes contributions to the series. Please contact Peter Lapsley (plapsley@bmj.com) for guidance.
\end{abstract}

In June 2011, aged 79, I was admitted to the orthopaedic ward of my local NHS teaching hospital for a revision of a loose 14 year old hip replacement. I was clerked in by an orthopaedic associate specialist but no anaesthetist arrived.

Next morning I met the consultant anaesthetist and the surgeon in the anaesthetic room. I recognised the anaesthetist as having given me a spinal block for a previous knee replacement. He proposed a combined spinal and epidural block with heavy sedation, to which I agreed.

I was returned to the ward about $4 \mathrm{pm}$. The orthopaedic associate came to tell me that all had gone as planned, and he confirmed my ability to raise and extend my legs. When the nurse started my routine checks I told her that I was completely numb in and around my groin. Later my wife was present when I again told nurses of my numbness. We were reassured by their explanation that the area was the last to recover and this might be delayed by the epidural pain relief. Even then I remembered I had not experienced this when I had my knee done.

When it was time to sleep I advised the nurse that I had not passed urine but had no desire to do so. As I was on intravenous fluids, I was surprised when I woke the next morning at about 6 am that I didn't need a bottle. However, I could palpate a suprapubic swelling, which I assumed was my bladder, even though pressure on it was not uncomfortable. I asked for a doctor as I believed I needed catheterisation. About 8 am a junior doctor arrived. After palpating my abdomen he called for a catheter tray and relieved me of about 1.5 litres of urine, with me unaware of any manipulation. Leaving me with an indwelling catheter attached to a bed bag, he departed without, it turned out, making any record in the notes or reporting to a senior doctor.
As it was a Friday, I expected a visit from the orthopaedic team, but only a specialist nurse in pain relief came to see me. I had minimal discomfort. In the afternoon I found I was lying on a wet sheet, with copious mucus covering my buttocks. As the nurses changed the sheet they discovered that the epidural tube had come out of my back which must have contributed to the wetness. That evening in my wife's presence I told the nurses my numbness was unchanged despite the loss of the epidural at an unknown time. One nurse suggested I would soon recover if she got into bed with me. I was amused, my wife was not.

On Friday night I could not sleep and requested night sedation, for which the duty doctor was called. When he arrived, after considerable delay, he was the same doctor who had passed my catheter. I learned that he was the general surgical foundation year 2 doctor covering orthopaedics out of hours.

On Saturday morning, my only visitors were a specialist nurse from orthopaedics, who said he would ring the anaesthetist, and the pain relief nurse. Subsequently I learned the anaesthetist was on annual leave and unavailable. By now I was aware of the uncomfortable numbness involving my buttocks and posterior thighs. Gas bubbles escaped in the mucus between my legs.

Sunday continued in a similar vein, with me confined to bed by foot pumps and without any medical visit. When my wife arrived in the late afternoon I told her of my increasing concern at being unable to raise medical interest in my condition, the aetiology of which had to be more complicated than delayed epidural recovery. My wife spoke to a houseman, who told her my problems would be dealt with on Monday.

When my wife returned home, she rang our daughter, a consultant rhinologist. She rang the ward and was told that the registrar could not be called because I was not an emergency. My daughter fortunately was able to ring the orthopaedic consultant at home to ask him, "What is wrong with my father?" About 9 pm, three junior doctors came in turn, armed with pins to contemplate the possibility of a cauda equina syndrome. On Monday morning I had a visit from my orthopaedic consultant, 
who ordered that I be starved in case of the need for further surgery. I then had an emergency magnetic resonance scan, and in the early evening the report was reviewed by a spinal surgeon, who told me of a haematoma lying posteriorly at L1-L2 and that he considered surgical decompression was not justified. The window of opportunity to bring a possible early recovery thus remained closed.

Space limitation does not allow the description of the unpleasantness of the two and a half weeks I spent in hospital. Care of incontinence was not on the same level as the kindness of the nurses. The urinary bed bag was changed to a flip-flow valve and, after discharge, to intermittent catheterisation. Both were easy to forget in the absence of bladder sensation, which led to several "accidents" when abdominal pressure was raised-for example, when standing or coughing.

After discharge, four episodes of haematuria, one of which caused an emergency admission, resulted in prolonged antibiotics and an attempt by my excellent urologist to get me off clopidogrel. Eight months after the operation I have stopped using catheters. My bladder started to function weakly at about seven weeks after surgery and gradually improved. It remains weak and lacks sensation. When I stand, a pain-like sensation tells me I must urinate. Fifteen minutes later I can pass almost the same amount again.

The back end remains a problem. I am not incontinent but I have some problems differentiating between gas and solids. The district incontinence service introduced me to the self administered Peristeen rectal washout system, paid for, as were the urinary catheters, by my general practice's budget. Now that the rectal catheter has been redesigned and the balloon does not burst, this is an excellent system, which prevents "accidents." However, the process is time consuming and there is a learning curve. I cannot empty normally but require the combination of abdominal muscle contraction, manual compression, and agitation of the abdomen. I use the Peristeen system almost every day.

The profound saddle anaesthesia has made a partial recovery. The perineal and buttock areas are dulled and paraesthesic. The perianal tissues have sensation but this is abnormal and the area feels isolated from the surrounding tissue. There is no sensation produced by the passage of solids.

Initially I seemed to be sitting on a log that was very uncomfortable. Now the sensation is of sitting on a leather strap with my tuberosities unprotected. The literature states the elderly male has a poorer prognosis for a full recovery with this presentation. Time will tell. Happily my hip functions reasonably well and I am due to have a knee replacement in about a month's time.

NHS healthcare delivery is rarely out of the media and there are frequent reports of misadventure. ${ }^{1}$ Medical students are apparently trained in teamwork and communication but not in the care of the ill. The presidents of the Royal College of Physicians and the Royal College of Surgeons have warned of the effect on junior doctors of the European Working Time Directive, shift work, days off, reduced hours, and clinical experience. Doctors' numbers may have increased but not their expertise. Similar problems exist in the nursing profession as nurses train to do the work that was previously the remit of doctors while leaving nursing to healthcare assistants.

The secretary of state for health has recognised there are problems in the NHS at weekends owing to the absence of senior doctors. My recent difficulties result from all of the above. Additionally there is a failure to train doctors and nurses adequately. If the discipline of anaesthesia recognises that central nerve blocks can cause complications with serious implications for patients, all of the staff who provide postoperative care must be trained to recognise them. Reluctance to contact senior staff for advice must be eliminated. Note taking and communication between nurses, between nurses and junior doctors, and between junior and senior doctors require rethinking. If consultants stop doing ward rounds and supervising junior doctors, it is necessary to redefine who is ultimately responsible for patient care. Instead of spending vast sums settling negligence claims ( $£ 1$ bn in 2010), would this money not be better used to provide increased staffing and training, particularly for out of hours care? As a non-medical friend said to me, "If they can't even look after you, who will they look after?"

Editorial note: Since this article was originally published online, two small amendments have been made. Gavin Werrett was not involved in Mr Hopkins's care, which did not take place at Derriford Hospital, where Dr Werrett works.

Competing interests: Both authors declare: no support from any organisation for the submitted work; no financial relationships with any organisations that might have an interest in the submitted work in the previous three years, no other relationships or activities that could appear to have influenced the submitted work.

Provenance and peer review: Not commissioned; not externally peer reviewed.

1 Royal College of Surgeons of England. Emergency surgery, standards for unscheduled surgical care. RCSEng, 2011. www.rcseng.ac.uk/publications/docs/emergency-surgerystandards-for-unscheduled-care/.

2 Cook TM, Counsell D, Wildsmith JA. Major complications of central neuraxial block: report on the Third National Audit Project of the Royal College of Anaesthetists. Br J Anaesth 2009;102:179-90.

Accepted: 11 April 2012

Cite this as: BMJ 2012;345:e5366

๑ BMJ Publishing Group Ltd 2012 


\section{A doctor's perspective}

This clearly has been a very distressing case for Mr Hopkins and it raises some interesting points.

A central neuraxial block such as a spinal and/or an epidural can be used as a sole anaesthetic technique or as an adjunct to general anaesthesia to facilitate postoperative pain management. In this case, a combined spinal and epidural technique was used to facilitate intraoperative anaesthesia and postoperative analgesia. In long operations such as revision of hip replacement, heavy sedation or a general anaesthetic is usually also administered.

The dense numbness that Mr Hopkins experienced in the perineal area is indeed normal after a spinal block, and it is the last area to return to normal, but sensation should return within six to 10 hours maximum. The concurrent or independent use of a lumbar epidural does complicate matters. Although it is routine practice in most hospitals to assess leg weakness hourly after an epidural is sited (to try to diagnose as early as possible any cases of nerve or cord damage associated with, for example, a haematoma or abscess), sensation is less commonly checked.

Clearly on catheterisation for a painless full bladder, it would not have been unreasonable to have questioned whether this was to be expected from an epidural. As the frequency of epidural use has dropped over the years, nurses' and juniors doctors' exposure to these advanced techniques has also diminished.

It seems that about 24 hours after returning to the ward, the epidural catheter had come out. It is fair to say that after this point, any residual weakness in the legs or numbness in the legs or perineum should have been attributable to nerve damage, until proved otherwise.

Unfortunately, it was over 48 hours after this point at which the possibility of a cauda equina syndrome was considered.

If neuraxial haematoma is suspected, then magnetic resonance imaging must be done as soon as possible, with an aim for surgical decompression ideally within eight hours to achieve the best neurological outcome. Thus, appropriate procedures must be in place for monitoring patients' post-spinal anaesthetics or those with epidurals in situ, with associated teaching packages for the ward staff.

Serious complications after both spinals and epidurals remain statistically very low, with the overall incidence of permanent (lasting more than six months) nerve damage reported as between 1 in 25000 and 1 in $50000{ }^{2}$

This is little comfort to Mr Hopkins.

Gavin Werrett, consultant anaesthetist 